One mutation, two phenotypes: a single nonsense mutation of the CTSC gene causes two clinically distinct phenotypes

\begin{tabular}{|c|c|}
\hline Journal: & Clinical and Experimental Dermatology \\
\hline Manuscript ID: & CED-2014-0810 \\
\hline Wiley - Manuscript type: & Experimental Original Article \\
\hline Date Submitted by the Author: & 23-Sep-2014 \\
\hline Complete List of Authors: & $\begin{array}{l}\text { Sulák, Adrienn; University of Szeged, Department of Medical Genetics } \\
\text { Tóth, Lola; University of Szeged, Department of Medical Genetics } \\
\text { Farkas, Katalin; University of Szeged, MTA SZTE Dermatological Research } \\
\text { Group } \\
\text { Tripolszki, Kornélia; University of Szeged, Department of Medical Genetics } \\
\text { Fábos, Beáta; Mór Kaposi Teaching Hospital, } \\
\text { Kemény, Lajos; University of Szeged, MTA SZTE Dermatological Research } \\
\text { Group } \\
\text { Vályi, Péter; University of Szeged, Department of Parodontology, Faculty of } \\
\text { Dentistry } \\
\text { Nagy, Katalin; University of Szeged, Department of Parodontology, Faculty } \\
\text { of Dentistry } \\
\text { Nagy, Nikoletta; University of Szeged, Department of Medical Genetics } \\
\text { Széll, Márta; University of Szeged, Department of Medical Genetics }\end{array}$ \\
\hline Keywords: & $\begin{array}{l}\text { Papillon-Lefévre syndrome, Haim-Munk syndrome, allelic variants, } \\
\text { cathepsin C gene, nonsense mutation }\end{array}$ \\
\hline
\end{tabular}


Original article

\title{
One mutation, two phenotypes: a single nonsense mutation of the CTSC gene causes two clinically distinct phenotypes
}

\begin{abstract}
A. Sulák, ${ }^{1 *}$ L. Tóth, ${ }^{1 *}$ K. Farkas, ${ }^{2}$ K. Tripolszki, ${ }^{1}$ B. Fábos, ${ }^{3}$ L. Kemény, ${ }^{2,4}$ P. Vályi, ${ }^{5}$ K. Nagy, ${ }^{5}$ N. Nagy, ${ }^{1,2,4}$ M. Széll, ${ }^{1,2}$

${ }^{1}$ Department of Medical Genetics, University of Szeged, Szeged, HUNGARY

${ }^{2}$ MTA SZTE Dermatological Research Group, University of Szeged, Szeged, HUNGARY

${ }^{3}$ Mór Kaposi Teaching Hospital, Kaposvár, HUNGARY

${ }^{4}$ Department of Dermatology and Allergology, University of Szeged, Szeged, HUNGARY

${ }^{5}$ Department of Parodontology, Faculty of Dentistry, University of Szeged, Szeged, HUNGARY

*These authors contributed equally to this work.
\end{abstract}

\section{Corresponding author:}

Adrienn Sulák, Department of Medical Genetics, University of Szeged

4 Somogyi Béla utca, H-6720 Szeged, HUNGARY

Tel:+36-62-545134, Email: sulak.adrienn@gmail.com

Key words: Papillon-Lefévre syndrome, Haim-Munk syndrome, allelic variants, cathepsin C gene, nonsense mutation

Manuscript word count: 1480 
Table count: 1

Figure count: 2

\section{Conflict of interest}

The authors declare that they have no conflict of interest.

Running head: A single mutation of the CTSC gene causes two phenotypes 


\title{
ABSTRACT
}

Background Papillon-Lefévre (PLS; OMIM 245000) and Haim-Munk syndromes (HMS; OMIM 245010) are phenotypic variants of the same rare disease caused by mutations of the cathepsin $C(C T S C)$ gene and exhibit autosomal recessive inheritance.

\begin{abstract}
Aims To identified the diseases causes mutations of the CTSC gene in the case of the patients and to perform haplotype analysis to elucidate that any familial relationship between the two investigated patients.
\end{abstract}

Methods Mutations were identified by direct sequencing of genomic DNA amplified for exonic regions of CTSC gene and haplotype analysis was performed.

Results Mutation screening of the CTSC gene from two Hungarian patients revealed the presence of the same heterozygous nonsense mutation (c.748C/T; p.Arg250X). However, one patient exhibited the PLS phenotype and the other the HMS phenotype. Although these patients were not aware that they were related, haplotype analysis revealed that they carry the same haplotype, and the possibility that they are related cannot be excluded.

Conclusions Our results support the hypothesis that PLS and HMS are the phenotypic variants of the same disease and, additionally, exclude the presence of a putative genetic modifier factor within the CTSC gene that is responsible for the development of the two phenotypes. We hypothesize that this putative genetic modifier factor is located outside the CTSC gene or, alternatively, that the development of the different phenotypes is the consequence of different environmental or life style factors. 


\section{INTRODUCTION}

Papillon-Lefévre (PLS; OMIM 245000) and Haim-Munk syndromes (HMS; OMIM 245010) are phenotypic variants of the same disease. PLS and HMS are characterized by overlapping dermatological and dental symptoms such as hyperkeratosis of the palms and soles as well as severe periodontitis. ${ }^{1,2}$ Patients with PLS can also develop mild mental retardation, calcification of the dura mater, hyperhidrosis and increased susceptibility to infections. ${ }^{3,4,5}$ Specific features of HMS include pes planus, arachnodactyly, acroosteolysis and onychogryphosis. ${ }^{6,7,8}$ The prevalence of PLS is approximately four cases per million, and, to date, approximately 300 cases have been reported worldwide. Parental consanguinity has been noted in more than $50 \%$ of these cases. ${ }^{4,9}$ The prevalence of HMS is approximately one case per million, and the majority of reported cases are descendants of a few consanguineous families from a religious isolate in Cochin, India. One unrelated Brazilian patient has also been reported. Fewer than 100 HMS cases have been reported in the literature to date. ${ }^{6,7,8}$ The ratio of affected males to females is 1:1 for both phenotypic variants. PLS and HMS are both inherited in an autosomal recessive manner and develop as a consequence of mutations of the cathepsin C (CTSC) gene. ${ }^{10,11}$ Currently, 75 CTSC gene mutations have been identified. ${ }^{1}$ The majority of these mutations ( 74 of $75,99 \%$ ), have been detected in PLS patients, whereas only $4 \%$ (three of 75 ), have been associated with HMS. ${ }^{1,2,7,8}$ Two mutations (c.145C/T, p.Gln49X and c.857A/G p.Gln286Arg) were present in patients exhibiting both PLS and HMS phenotypes. Only one mutation (c.587T/C p.Leu196Pro) has been associated exclusively with HMS. ${ }^{2,8,12,13}$

Here we report two Hungarian patients affected by different phenotypic variants, one with PLS and one with HMS, who nonetheless carry the same homozygous nonsense mutation (c.748C/T; p.Arg250X) of the CTSC gene. Polymorphisms surrounding the mutation were 
investigated to determine whether these patients are relatives and to possibly identify a genetic modifier factor within the CTSC gene, which could be responsible for the development of the different phenotypes.

\section{MATERIALS AND METHODS}

\section{Patients}

Both patients were referred to the out-patient clinic of the Mór Kaposi Teaching Hospital (Kaposvár; Hungary).

A 39-year-old Hungarian woman (Patient I) presented with a typical HMS phenotype. Mild hyperkeratotic plaques were observed symmetrically on her palms (Fig. 1a) and soles (Fig. 1c). Onychogryphosis and arachnodactyly were noted on her fingers (Fig. 1b) and pes planus on her soles (Fig. 1b). The patient lost all permanent teeth and uses a permanent dental prosthesis. She was brought up in state care without knowing her parents and has no husband or child. She was not aware of any known relatives.

A 25-year-old Hungarian man (Patient II) presented with the classical PLS phenotype. The hyperkeratosis on his palms (Fig. 1d) and soles (Fig. 1e) was more severe than the symptoms of Patient I. Onychogryphosis, arachnodactyly and pes planus were not present. He was also missing all permanent teeth and using a permanent dental prosthesis. His parents and his wife were clinically unaffected. He had no siblings or children. He was not aware of any family members that are clinically affected (Fig. 1f).

\section{Genetic investigation}

Blood samples were taken from the two investigated patients and from unrelated controls for genetic investigation. Genomic DNA was isolated with a BioRobot EZ1 DSP Workstation (QIAGEN; Godollo, Hungary). After amplifying the coding regions and flanking introns of 
the CTSC gene (using primer sequences displayed on the UCSC Genome Browser, http://www.genome.ucsc.edu), DNA sequencing was performed on amplification products. Sequencing data was analyzed to screen for any additional mutations and to genotype all the common polymorphisms of the CTSC gene. Based on the polymorphism data, haplotype analysis was performed to elucidate any familial relationship between the two investigated patients. The polymorphism data were compared in an attempt to identify a putative genetic modifier variant within the CTSC gene that could be responsible for the observed differences in the phenotypes of the patients.

Written informed consent was obtained from all investigated individuals, and the study was conducted according to the Principles of the Declaration of Helsinki.

\section{RESULTS}

Direct sequencing of the coding regions of the CTSC gene from Patient I and Patient II revealed a nonsense mutation in the fifth exon (c.748C/T, p.Arg250X). The patients carried the mutation in homozygous form (Fig. 2a), while the unrelated controls carried the wild type sequence (Fig. 2b).

The presence of the same homozygous nonsense mutation in both patients raised the possibility of familial relationship between them. To address this, the polymorphisms located in the $3^{\prime}$ and $5^{\prime}$ regions of the identified mutation were genotyped and the haplotypes were determined. The patients were homozygous for all the genotyped polymorphisms, and all genotypes were the same for both patients, indicating they carried exactly the same haplotype (Table I).

Since the patients presented different phenotypes (i.e., HMS and PLS), but carried the same homozygous nonsense mutation, further screening was performed to identify a putative 
second genetic modifier variant within the CTSC gene. A comparison of all polymorphism and genotypes of the coding regions and flanking introns of the CTSC gene did not reveal any genetic difference between the two patients: they both carried exactly the same genotypes regarding all the investigated polymorphisms (Table I).

\section{DISCUSSION}

Currently, 75 different mutations have been reported worldwide for the CTSC gene. ${ }^{1}$ Nonsense mutations, accounting for $23 \%(\mathrm{n}=17)$ of pathogenic CTSC mutations, occur in all coding regions of the gene; however the majority is located in exons 5-7, which encodes the heavy chain region of the cathepsin $\mathrm{C}$ protein. ${ }^{1,14}$ This protein is a lysosomal cysteine protease, and the heavy chain region is important for enzyme activity. ${ }^{14,15}$ The p.Arg250X homozygous nonsense mutation detected in the investigated patients is also located in this region. The p.Arg250X mutation leads to the formation of a truncated protein and may significantly impair enzyme activity. This hypothesis correlates well with previous studies demonstrating that pathological changes in the CTSC gene are loss-of-function mutations resulting in the inactivation of enzymatic activity and altered regulation of the immune response, which increase the susceptibility tp periodontal inflammation and skin infections. ${ }^{16,17}$

The p.Arg250X nonsense mutation has already been previously reported in patients with PLS ${ }^{18,19}$ however, this is the first report of its association with HMS. The mutation has been previously detected in homozygous ${ }^{18}$ and in compound heterozygous forms. ${ }^{19}$ The latter mutation was suggested to be associated with an unidentified heterozygous mutation of the CTSC gene. ${ }^{19}$ A previous investigation detected this mutation in homozygous form in Turkish 
patients. $^{18}$ It is likely that these Turkish and Hungarian PLS patients have a common haplotype (Table I) and the identified mutation is the consequence of a single founder effect. The two investigated Hungarian patients were affected by different variants (PLS and HMS) of the phenotypic spectrum caused by CTSC mutations. Clinical differences between the PLS and HMS symptoms of the patients were striking, although, surprisingly, genetic screening identified the presence of the same nonsense mutation (p.Arg250X) in homozygous form in both patients. Haplotype analysis revealed that the two patients exhibit the same haplotype (Table I), indicating a strong likelihood of relatedness. The patients were not aware of any such relationship. Patient I was brought up in state care and did not know any of her relatives. Patient II was not aware of consanguinity within his family. However, our results and the fact that they share a common family name strongly suggest familial relationship between the two investigated patients.

As the patients had the same homozygous disease-causing mutation as well as the same haplotype, it was possible to examine genetic variations in the CTSC gene to identify any differences that could account for the development of the phenotypic differences. Our investigation could not identify any such genetic variant with the CTSC gene and flanking regions. Therefore, we hypothesize that the putative modifier factor, which results in the development of different phenotypic variants for this CTSC mutation, is not located in the region of CTSC, but in another region. Moreover, we cannot exclude the possibility that the reason for the phenotypic variation is a non-genetic influence, such as environmental or life style factors.

Our results further support the accepted viewpoint that PLS and HMS are not different disease entities, but that they are phenotypic variants of the same disease and their development is influenced by other factors. This phenomenon has also been observed in another group of rare monogenic diseases caused by mutations in the CYLD gene. Initially, Brooke-Spiegler 
syndrome (BSS; OMIM 605041), multiple familial trichoepithelioma type 1 (MFT1; OMIM 601606) and familial cylindromatosis (FC; OMIM 132700) were considered different entities, until genetic investigation revealed that they were allelic variants of the same disease. ${ }^{20,21}$ These observations highlight the importance of genetic investigation and the establishment of genotype-phenotype associations. 


\section{ACKNOWLEDGEMENTS}

This study was supported by the following Hungarian grants: TÁMOP-4.2.2.A-11/1/KONV2012-0035, TÁMOP-4.2.2/B-10/1/KONV-2010-0012， TÁMOP-4.2.4.A/2-11-1-2012-0001 and TÁMOP-4.2.2.A3. Nikoletta Nagy was supported by the Hungarian Scientific Research Foundation (OTKA) PD104782 2012-2015 grant. This research was supported by the European Union and the State of Hungary, co-financed by the European Social Fund in the framework of TÁMOP-4.2.4.A/ 2-11/1-2012-0001 "National Excellence Program." 


\section{REFERENCES}

1. Nagy N, Vályi P, Csoma Zs et al. CTSC and Papillon-Lefèvre syndrome: detection of recurrent mutations in Hungarian patients, a review of published variants and database update. Mol Gen \& Genom Med 2014; 2: 217-28.

2. Selvaraju V, Markandaya M, Prasad PV et al. Mutation analysis of the cathepsin C gene in Indian families with Papillon-Lefèvre syndrome. BMC Med Genet 2003; 4: 5.

3. Dalgic B, Bukulmez A, Sari S. Eponym: Papillon-Lefevre syndrome. Eur J Pediatr 2011; 170: 689-91.

4. Gorlin RJ, Sedano H, Anderson VE. The syndrome of palmar-plantar hyperkeratosis and premature periodontal destruction of the teeth: a clinical and genetic analysis of the Papillon-Lefevre syndrome. J Pediat 1964; 65: 895-908.

5. Haneke E. The Papillon-Lefevre syndrome: keratosis palmoplantaris with periodontopathy: report of a case and review of the cases in the literature. Hum Genet 1979; 51: 1-35.

6. Haim S, Munk J. Keratosis palmo-plantaris congenita, with periodontosis, arachnodactyly and a peculiar deformity of the terminal phalanges. $\mathrm{Br} J$ Dermatol 1965; 77: 42-54. 
7. Hart TC, Hart PS, Bowden DW et al. Mutations of the cathepsin C gene are responsible for Papillon-Lefevre syndrome. J Med Genet 1999; 36: 881-7.

8. Papillon PH, Lefèvre P. Deuxcas de kératodermiepalmaire et plantairesymétriquefamiliale (maladie de Meleda) chez le frère et la soeur. Coexistence dans les deuxcasd'altérations dentaires graves. Bulletin de la Société française de dermatologie et de vénéorologie, Paris 1924; 31: 82-7.

9. Hewitt C, McCormick D, Linden G et al. The role of cathepsin C in Papillon-Lefevre syndrome, prepubertal periodontitis, and aggressive periodontitis. Hum Mutat 2004; 23: $222-8$.

10. Adkison AM, Raptis SZ, Kelley DG et al. Dipeptidyl peptidase I activates neutrophil-derived serine proteases and regulates the development of acute experimental arthritis. J Clin Invest 2002; 109: 363-71.

11. Toomes C, James J, Wood AJ et al. Loss-of-function mutations in the cathepsin C gene result in periodontal disease and palmoplantar keratosis. Nat Genet 1999; 23: 421-4.

12. Cury VF, Costa JE, Gomez RS et al. A novel mutation of the cathepsin $\mathrm{C}$ gene in Papillon-Lefevre syndrome. J Periodontol 2002; 75: 307-12. 
13. Turk D, Janjic V, Sitern I et al. Structure of human dipeptidyl peptidase I (cathepsin C): exclusion domain added to an endopeptidase framework creates the machine for activation of granular serine proteases. EMBO J 2011; 20: 6570-82.

14. Hart PS, Zhang Y, Firatli E et al. Identification of cathepsin C mutations in ethnically diverse Papillon-Lefevre syndrome patients. J Med Genet 2000; 37: 927-32.

15. Korkmaz B, Horwitz MS, Jenne DE et al. Neutrophil elastase, proteinase 3, and cathepsin G as therapeutic targets in human diseases. Pharmacol Rev 2010; 62: 72659.

16. Hart TC, Hart PS, Michalec MD et al. Haim-Munk syndrome and Papillon-Lefevre syndrome are allelic mutations in cathepsin C. J Med Genet 2000; 37: 88-94.

17. Rai R, Thiagarajan S, Mohandas S et al. HaimMunk syndrome and Papillon Lefevre syndrome--allelic mutations in cathepsin $\mathrm{C}$ with variation in phenotype. Int $J$ Dermatol 2010; 49: 541-3.

18. Cury VF, Gomez RS, Costa JE et al. A homozygous cathepsin C mutation associated with Haim-Munk syndrome. Br J Dermatol 2005; 152: 353-6.

19. Pham CT, Ivanovich JL, Raptis SZ et al. Papillon-Lefevre syndrome: correlating the molecular, cellular, and clinical consequences of cathepsin $\mathrm{C} /$ dipeptidyl peptidase I deficiency in humans. J Immunol 2004; 175: 7277-81. 
20. Nagy N, Rajan N, Farkas K et al. A mutational hotspot in CYLD causing cylindromas: a comparison of phenotypes arising in different genetic backgrounds. Acta Derm Venereol 2013; 93: 743-5.

21. Rajan N, Burn J, Langtry $\mathrm{J}$ et al. Transition from cylindroma to spiradenoma in CYLD-defective tumours is associated with reduced DKK2 expression. J Pathol 2011; 224: 309-21. 


\section{FIGURE LEGENDS}

Figure 1. Skin symptoms of two Hungarian patients. Patient I, presenting with HMS, exhibited mild hyperkeratosis on her palms (a), onychogryphosis and arachnodactly of her fingers (b) and mild hyperkeratosis and pes planus on her soles (c). Patient II, presenting with PLS, was affected by moderate hyperkeratosis of his palms (d) and soles (f) and exhibited no specific symptoms of HMS. Patient I was brought up in state care without knowing her relatives. No other affected individuals are known in the family of Patient II (e).

Figure 2. Mutation screening of the CTSC gene. Direct sequencing revealed a nonsense mutation (c.748C/T, p.Arg250STOP) in the fifth exon of the CTSC gene. Both Patient I and II carried the mutation in homozygous form (a), while all the unrelated healthy control individuals carried the wild type sequence (b). 
Table I. Haplotype analysis. Patient I and II exhibited the same haplotype.

\begin{tabular}{|c|c|c|c|}
\hline Polymorphisms & $\begin{array}{c}\text { Common } \\
\text { allele }\end{array}$ & Patient I. & Patient II. \\
\hline rs116702910 & $\mathrm{T}$ & $\mathrm{TT}$ & $\mathrm{TT}$ \\
\hline rs77499989 & A & $\mathrm{AA}$ & $\mathrm{AA}$ \\
\hline rs144951351 & $\mathrm{T}$ & TT & TT \\
\hline rs150778155 & GAAA & GAAA & GAAA \\
\hline rs60736750 & $\mathrm{C}$ & $\mathrm{CC}$ & $\mathrm{CC}$ \\
\hline rs150294063 & $\mathrm{T}$ & $\mathrm{TT}$ & TT \\
\hline rs186157569 & A & $\mathrm{AA}$ & AA \\
\hline rs112016678 & $\mathrm{C}$ & $\mathrm{CC}$ & $\mathrm{CC}$ \\
\hline rs147642061 & $\mathrm{T}$ & TT & TT \\
\hline CM002938* & $\mathrm{C}$ & TT & TT \\
\hline rs200799436 & $\mathrm{T}$ & TT & TT \\
\hline rs217116 & $\mathrm{T}$ & TT & TT \\
\hline rs141174591 & G & GG & GG \\
\hline rs115099408 & $\mathrm{C}$ & $\mathrm{CC}$ & $\mathrm{CC}$ \\
\hline rs147844154 & G & GG & GG \\
\hline rs217115 & A & AA & $\mathrm{AA}$ \\
\hline rs 74325198 & $\mathrm{~T}$ & TT & TT \\
\hline rs181513908 & A & $\mathrm{AA}$ & $\mathrm{AA}$ \\
\hline rs188791825 & G & GG & GG \\
\hline
\end{tabular}

*The identified homozygous nonsense mutation (c.748C/T p.Arg250X) 
Figure 1. Skin symptoms of two Hungarian patients. Patient I, presenting with HMS, exhibited mild hyperkeratosis on her palms (a), onychogryphosis and arachnodactly of her fingers (b) and mild hyperkeratosis and pes planus on her soles (c). Patient II, presenting with PLS, was affected by moderate hyperkeratosis of his palms (d) and soles (f) and exhibited no specific symptoms of HMS. Patient I was brought up in state care without knowing her relatives. No other affected individuals are known in the family of Patient II (e). 
Clinical and Experimental Dermatology

Page 18 of 18

(a)

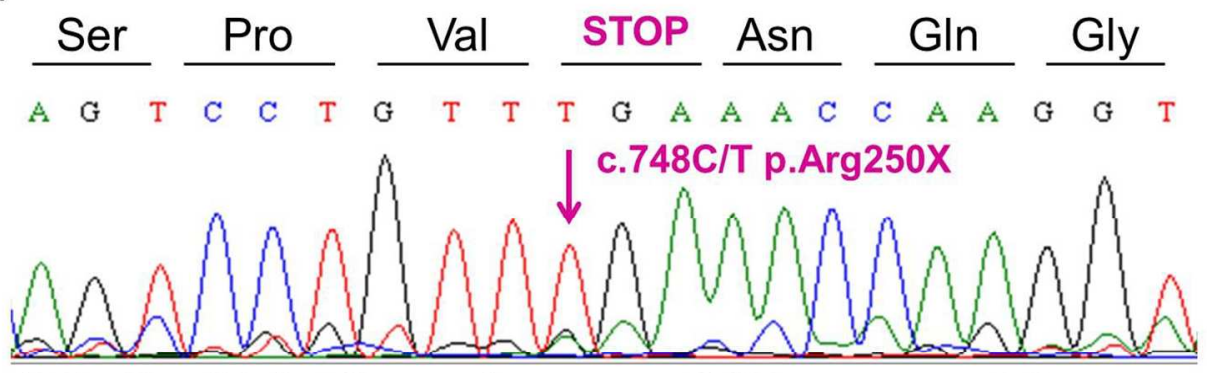

Patient I and Patient II carry a homozygous CTSC nonsense mutation.

(b)

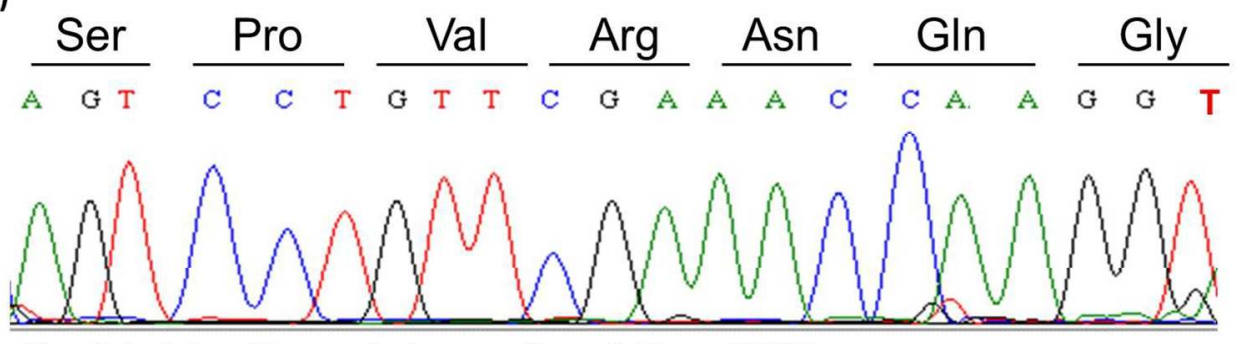

Unrelated, healthy controls carry the wild type CTSC sequence.

Figure 2. Mutation screening of the CTSC gene. Direct sequencing revealed a nonsense mutation (c. $748 \mathrm{C} / \mathrm{T}$, p.Arg250STOP) in the fifth exon of the CTSC gene. Both Patient I and II carried the mutation in homozygous form (a), while all the unrelated healthy control individuals carried the wild type sequence (b).

$$
241 \times 173 \mathrm{~mm}(150 \times 150 \mathrm{DPI})
$$

